\title{
Mecanismos de ação de isolados de leveduras envolvidos no biocontrole de Penicillium digitatum, agente causal do bolor verde em frutos cítricos
}

\author{
Luriany Pompeo Ferraz ${ }^{1}$, Tatiane da Cunha ${ }^{1} \&$ Katia Cristina Kupper ${ }^{2}$ \\ RESUMO
}

O bolor verde, causado por Penicillium digitatum, é considerado a principal doença de pós-colheita em frutos cítricos. Os fungicidas benzimidazóis são os mais utilizados no Brasil para o controle, porém, têm várias restrições de uso, como o de selecionar linhagens resistentes do fitopatógeno pelo uso intensivo dos produtos. Portanto, a busca por métodos alternativos de controle se faz necessário e, dentre esses, o uso de leveduras tem demonstrado um grande potencial no controle de doenças que ocorrem na pós-colheita de cítros. No entanto, os mecanismos de ação que estão envolvidos na atividade antagonista são ainda pouco conhecidos. Assim, o presente estudo teve por objetivo avaliar o modo de ação de oito isolados de levedura, obtidos do filoplano de plantas cítricas de diferentes municípios do estado de São Paulo, que em estudos prévios, apresentaram potencial de controle do bolor verde em frutos cítricos. Os resultados obtidos mostraram que a atividade killer e a produção de quitinase podem ser os principais mecanismos de ação das leveduras no controle de $P$. digitatum. Este trabalho sugere que os múltiplos modos de ação (produção de toxinas killer, atividade enzimática e inibição da germinação do patógeno) apresentados por ACBL-80, ACBL-82 e ACBL-86 indicam serem esses microrganismos candidatos em potencial para o biocontrole do bolor verde.

Termos de indexação: germinação, fator killer, enzimas hidrolíticas.

\section{Action mechanisms of yeast isolates involved in the biocontrol of Penicillium digitatum, causal agent of green mold in citrus fruits}

\section{SUMMARY}

Green mold, caused by Penicillium digitatum, is considered the main postharvest disease of citrus. Fungicides of benzimidazoles group are the most used in Brazil for its control, however, have several restrictions for use, among these, as to select resistant strains of the pathogen to the main active ingredient. Therefore, the search for alternative products for disease control is necessary and, among these, the use of yeast has shown potential to biocontrol in citrus fruits. However, little is known about the mechanisms involved in the antagonistic activity. So the present study aimed to evaluate the mechanisms of action from eight strains of yeast, obtained from the phylloplane of citrus

\footnotetext{
${ }^{1}$ Programa de Pós-graduação em Microbiologia Agropecuária, Faculdade de Ciências Agrárias e Veterinárias, Universidade Estadual Paulista - UNESP, Jaboticabal, SP, Brasil

${ }^{2}$ Centro de Citricultura Sylvio Moreira, Instituto Agronômico, Cordeirópolis, SP, Brasil

Autor correspondente: Katia Cristina Kupper, Centro de Citricultura Sylvio Moreira, Instituto Agronômico, Rodovia Anhanguera, Km 158, CEP 13490-970, Cordeirópolis, SP, Brasil. E-mail: katia@centrodecitricultura.br
} 
plants from different counties of São Paulo state, that showed potential for control of green mold in previous studies. The results obtained in this study showed that killer activity and chitinase production can be the main mechanisms of action adopted by the yeast isolates for the biocontrol of $P$. digitatum. This work suggests that multiple modes of action (killer toxin production, enzyme activity, and inhibition of conidial germination of the pathogen) presented by ACBL-80, ACBL-82 and ACBL-86, imply these microorganisms are strong candidates for biological control agents of green mold.

Index terms: germination, factor killer, hidrolytic enzymes.

\section{INTRODUÇÃO}

Os maiores países produtores de laranjas são o Brasil e os Estados Unidos, sendo que, no Brasil, em particular, a estimativa de safra de laranja 2016/2017 do cinturão citrícola de São Paulo e triângulo/Sudoeste mineiro foi mantida em 244,20 milhões de caixas de 40,8kg cada, segundo dados da FUNDECITRUS (2017).

Diante da importância econômica que a cultura representa para a economia nacional, os cuidados e a preocupação dos agricultores com a obtenção de frutas cítricas de qualidade e livres de patógenos são constantemente almejados. Dentre as doenças que ameaçam o setor citrícola, as doenças que ocorrem na fase de pós-colheita afetam a produção e a qualidade dos frutos e, dentre essas, o bolor verde, causado por Penicillium digitatum (Pers.) Sacc. 1881 é considerado a doença mais importante. Esse fungo está disseminado em todos os países produtores, afetando todas as espécies e variedades cítricas (Eckert \& Eaks, 1989).

Atualmente, o controle do bolor verde no packing-house, baseia-se no tratamento de frutos com fungicidas, como imazalil (IMZ) e tiabendazol (TBZ). Estes fungicidas são utilizados sozinhos ou, em misturas, ou aplicados separadamente em sequencia, sendo os mesmos utilizados há mais de 25 anos (Ismail \& Zhang, 2004). No entanto, estes princípios ativos possuem várias restrições de uso, devido à seleção de linhagens resistentes do patógeno com o uso intensivo destes produtos (Bus et al., 1991; Zhu et al., 2006; Schmidt et al., 2006; Boubaker et al., 2009). A situação se agrava no caso de frutos para exportação, uma vez que existem diferenças entre as legislações dos países consumidores quanto à aceitação de determinados fungicidas, bem como, da concentração tolerada de resíduos nos frutos (Franco \& Bettiol, 2000).

Considerando a possibilidade do surgimento de linhagens resistentes aos princípios ativos utilizados; aliado ao fato da demanda da sociedade por produtos orgânicos e isentos de resíduos (Palou et al., 2002; Duffy et al., 2003; Zhu et al., 2006; Kinay et al., 2007) e os problemas relacionados à saúde pública, tem-se tornado imprescindível a busca de alternativas de controle dessas doenças.

Como alternativa de controle, as leveduras são potencialmente efetivas, pois são fenotipicamente mais adaptadas nas superfícies de folhas, fruto e vegetais, além de serem hábeis na colonização e competição por espaço e nutrientes (Filonow, 1998), o que dá a esse grupo de microrganismos vantagens quanto à utilização como agentes de biocontrole de patógenos na pós-colheita.

Espécies de leveduras vêm sendo utilizadas como agentes de biocontrole contra fitopatógenos não só em citros, mas em diferentes culturas (Jijakli \& Lepoivre, 1998; Masih et al., 2001; Kupper et al., 2013) e, muitas já são encontradas comercialmente, como é o caso de Candida oleophila e Cryptococcus albidus registradas como Aspire ${ }^{\circledR}$ (Ecogen Inc., Langhorn, PA) e YieldPlus ${ }^{\circledR}$ (Anchor Yeast, Cape Town, South Africa), respectivamente (Droby et al., 2002).

Apesar do conhecimento sobre algumas funções das leveduras no ambiente, muito ainda há para ser descoberto, principalmente sobre os seus mecanismos de ação (Rosa-Magri et al., 2011). Algumas espécies de leveduras produzem enzimas hidrolíticas tais como $\beta$ - glucanases e quitinases, que destroem as paredes celulares de outros fungos (Saligkarias et al., 2002). Outras leveduras, como a Pichia membranifaciens (CYC 1106) produz toxina killer que controla Botrytis cinerea, agente causal do bolor cinzento em maçãs (Santos et al., 2004).

Em estudos prévios (Cunha, 2013) foi verificado o potencial de oito isolados de leveduras em controlar o bolor verde em frutos de laranja. No entanto, o mecanismo de ação desses organismos na atividade antagonista não foi estudado. Compreender esses mecanismos é um pré-requisito para o desenvolvimento de métodos de produção e formulação mais consistentes do antagonista. Portanto, o presente trabalho teve como objetivo, estudar e avaliar os possíveis mecanismos de ação dessas leveduras que poderiam estar envolvidos no biocontrole de $P$. digitatum. 


\section{MATERIAL E MÉTODOS}

\section{Microrganismos}

Os isolados de leveduras ACBL-76, ACBL-78, ACBL-80, ACBL-81, ACBL-82, ACBL- 84, ACBL-86, ACBL-87 e o isolado de Penicillium digitatum, utilizados neste estudo, pertencem à coleção de microrganismos do Laboratório de Fitopatologia e Controle Biológico do Centro de Citricultura "Sylvio Moreira"/IAC, Cordeirópolis/ SP, Brasil.

\section{Produção de compostos antifúngicos pelos isolados de leveduras}

Produção de compostos antifúgicos voláteis

Para a determinação da produção de compostos voláteis cultivou-se o fungo, simultaneamente, com os isolados de leveduras, utilizando placas bipartidas, as quais impedem que exsudatos não voláteis tenham contato com o fungo através do meio de cultura. Para tal, um disco de $5 \mathrm{~mm}$ de diâmetro de P. digitatum foi depositado em um dos lados da placa, contendo meio de cultura batata-dextrose-ágar (BDA), e do outro lado, contendo meio YEPD (extrato de levedura, peptona, glicose e ágar), foi depositado um disco (de mesmo tamanho) de cada isolado de levedura. Após 10 dias de incubação das culturas a $26^{\circ} \mathrm{C}$ foi realizada a avaliação, medindo-se o diâmetro micelial do $P$. digitatum em dois sentidos perpendiculares e, comparada ao cultivo do fungo na placa controle (sem a presença da levedura), de acordo com a metodologia descrita por Lopes et al. (2015).

\section{Produção de compostos antifúngicos livres de células da levedura}

Para cada isolado de levedura, uma alçada do microrganismo foi retirada de colônia ativa (48 horas de cultivo em YEPD) e transferida para frascos de Erlenmeyers de $250 \mathrm{~mL}$ contendo $50 \mathrm{~mL}$ de meio YEPD. Em seguida, as culturas foram incubadas sob agitação a 150 rpm, na ausência de luz por 72 horas.

Em seguida, a cultura correspondente a cada isolado foi filtrada em papel de filtro (Whaltman $\mathrm{n}^{\circ} 4$ ) e em membrana Millipore ${ }^{\circledast}(0,45 \mu \mathrm{M})$, a fim de se obter um filtrado livre de células de levedura (adaptação da técnica de Frighetto \& Melo (1995). Amostras de $10 \mathrm{~mL}$ de cada filtrado foram transferidas para $90 \mathrm{~mL}$ de BDA fundente. Obtidos os meios correspondentes a cada tratamento, os mesmos foram vertidos em placas de Petri e, após a solidificação, um disco de meio de cultura de $5 \mathrm{~mm}$ de diâmetro, contendo o fitopatógeno, foi transferido para o centro das placas. O controle correspondeu ao fitopatógeno cultivado em meio BDA sem a adição dos filtrados de células. As culturas foram incubadas em estufa para BOD a $26^{\circ} \mathrm{C}$ durante sete dias em fotoperíodo de $12 \mathrm{~h}$ e, a avaliação foi efetuada por meio da medição do diâmetro médio da colônia do P. digitatum.

\section{Produção de compostos antifúngicos termoestáveis}

Para cada isolado de levedura um disco de meio com o crescimento do microrganismo foi colocado em frascos Erlenmeyer de $250 \mathrm{~mL}$ contendo $50 \mathrm{~mL}$ de meio YEPD, e incubado sob agitação de $150 \mathrm{rpm}$, no escuro por 72 horas, como citado no item 2.2.2. Em seguida, amostras de $10 \mathrm{~mL}$ de cada isolado de levedura foram transferidas para frascos contendo $90 \mathrm{~mL}$ de BDA e, esterilizadas em autoclave a $121{ }^{\circ} \mathrm{C}$ por 20 minutos.

Obtidos os meios correspondentes a cada tratamento, os mesmos foram vertidos para placas de Petri e, após a solidificação, um disco de meio de cultura de $5 \mathrm{~mm}$ de diâmetro contendo o fitopatógeno foi transferido para o centro das placas. O controle correspondeu ao patógeno crescido em meio BDA sem a presença dos metabólitos. As culturas foram incubadas em estufa para BOD a $26^{\circ} \mathrm{C}$ durante sete dias e, a avaliação foi efetuada por meio da medição do diâmetro médio da colônia de $P$. digitatum.

\section{Detecção da atividade killer}

Para esse ensaio foi preparado, inicialmente, uma suspensão $\left(1 \times 10^{5}\right.$ células $\left.\mathrm{mL}^{-1}\right)$ de Saccharomyces cerevisiae NCYC 1006 (sensível ao fator killer), após cultivo em meio YEPD por 24 horas à $28{ }^{\circ} \mathrm{C}$. Uma alíquota de $100 \mu \mathrm{L}$ desta suspensão foi, então, espalhada sobre o meio de cultura YEPD + azul de metileno, tamponado a $\mathrm{pH} 4,3-4,7$, segundo a metodologia descrita por Ceccato-Antonini et al. (2004). Após secagem, os isolados de leveduras, a serem testados quanto à presença do fator killer, foram inoculados com palitos estéreis (em pontos), sendo a seguir, as culturas incubadas a $28^{\circ} \mathrm{C}$, por três 
dias. Os isolados foram considerados micocinogênicos (produtores de toxina Killer) quando produziram um halo de inibição de crescimento e zona azul adjacente, indicando a morte celular da levedura sensível.

\section{Competição por nutrientes}

Para a detecção da competição de nutrientes, entre o $P$. digitatum e a levedura antagonista, lâminas de microscopia contendo meio ágar-água com diferentes concentrações de glicose $(0,0 ; 0,5 ; 1 ; 1,5 ; 2$ e $2,5 \%)$ foram preparadas de acordo com metodologia descrita por Kupper et al. (2013). Posteriormente, $10 \mu \mathrm{L}$ de uma suspensão de $1 \times 10^{5}$ conídios $\mathrm{mL}^{-1}$ do fitopatógeno e $10 \mu \mathrm{L}$ de uma suspensão de $1 \times 10^{8}$ células $\mathrm{mL}^{-1}$ de cada isolado de levedura foram depositados em locais pré-demarcados das lâminas. As culturas foram incubadas em estufa para BOD a $26^{\circ} \mathrm{C}$ por 16 horas. A competição por nutrientes foi avaliada contando o número de conídios germinados, num total de 100 conídios selecionados ao acaso. Foi considerado germinado o conídio cujo tamanho do tubo germinativo encontrava-se maior ou igual ao tamanho do conídio.

\section{Avaliação do crescimento micelial do fitopatógeno retirado da zona de antagonismo}

Os isolados de leveduras foram pareados com o $P$. digitatum seguindo a metodologia descrita por Dennis \& Webster (1971). O teste foi realizado em placa de Petri, em meio de cultura BDA, no qual foi colocado de um lado, o fitopatógeno (disco de micélio com $5 \mathrm{~mm}$ de diâmetro) e à $3 \mathrm{~cm}$ de distância foi depositada a levedura (disco de $5 \mathrm{~mm}$ de diâmetro).

A partir da observação do halo de inibição entre os isolados de leveduras antagônicos e o fungo, após cultivo pareado em placa de Petri, foi realizado um experimento para quantificar o crescimento micelial do patógeno retirado da zona de antagonismo (micélio localizado adjacente do halo de inibição de crescimento fúngico), com o intuito de verificar se as hifas encontravam-se viáveis. Com o objetivo de comparação do crescimento micelial, foram realizadas retiradas de micélio fúngico (disco de $5 \mathrm{~mm}$ de diâmetro) de placas apresentando antagonismo, de três diferentes locais: na região de inibição, na região mediana (próxima ao halo de inibição) e, para fins de comparação, do micélio longe da levedura (onde o micélio não está sofrendo a ação inibitória da levedura). As culturas foram incubadas por 10 dias em estufa para BOD a $26^{\circ} \mathrm{C}$ em fotoperíodo 12 horas. A avaliação constou da medição do diâmetro do crescimento micelial do patógeno, em dois sentidos perpendiculares.

\section{Produção de enzimas hidrolíticas}

Este experimento teve por objetivo avaliar a produção e liberação de enzimas hidrolíticas pelos isolados de leveduras, seguindo a metodologia de Fialho (2005). Os isolados foram transferidos através de uma alça de inoculação para $20 \mathrm{~mL}$ de meio YEPD líquido e incubados sob agitação constante de $150 \mathrm{rpm}$ por 72 horas no escuro. Após esse período, $1 \mathrm{~mL}$ da suspensão foi transferida para tubos Falcon de $15 \mathrm{~mL}$ contendo $10 \mathrm{~mL}$ de meio YEPD e YEPD modificado (com preparado de parede celular do fungo testado, a $1 \%$ em substituição à glicose). $\mathrm{O}$ cultivo foi realizado em triplicata, sob agitação a $150 \mathrm{rpm}$. No tempo de 24 horas de incubação, uma amostra de $1,5 \mathrm{~mL}$ foi retirada e centrifugada a $3000 \mathrm{rpm}$ por $10 \mathrm{~min}$. O sobrenadante foi recuperado e utilizado para análise das atividades de $\beta$-1,3-glucanase e quitinase.

Para a preparação da parede celular (PPC), $1 \mathrm{~mL}$ da suspensão de esporos $\left(1 \times 10^{5}\right.$ esporos $\left.\mathrm{mL}^{-1}\right)$ do fitopatógeno foi cultivado em $50 \mathrm{~mL}$ de meio batata dextrose por oito dias, sob agitação constante à $150 \mathrm{rpm}$. O micélio fúngico foi coletado por filtração em papel de filtro Whatman $\left(n^{0} 1\right)$, lavado três vezes com água destilada e homogeneizado em tampão fostafo $0,1 \mathrm{M}(\mathrm{pH} 7,2)$ por 2 minutos e mantido a $-20^{\circ} \mathrm{C}$ overnight. Posteriormente, o material foi descongelado e novamente homogeneizado. Em seguida, aproximadamente $20 \mathrm{~mL}$ do micélio fúngico foi transferido para um frasco onde foi macerado com nitrogênio líquido e a parede celular do fungo foi armazenada em freezer $-80{ }^{\circ} \mathrm{C}$ para utilização posterior. Metodologia adaptada de Bar-Shimon et al. (2004).

\section{Atividades enzimáticas: $\beta$-1,3-glucanase e quitinase}

A determinação de açúcares redutores, liberados durante os ensaios enzimáticos, foi realizada segundo a metodologia descrita por Miller (1959), utilizando o reagente de ácido 3,5-dinitrosalicílico (ADNS). Para tal, $250 \mu \mathrm{L}$ da mistura de reação foram adicionados a $250 \mu \mathrm{L}$ do reagente ADNS e a solução foi aquecida em banho com água fervente por 10 minutos. Após o resfriamento 
em gelo, até a temperatura de $25^{\circ} \mathrm{C}$, a solução foi diluída com 2,5 mL de água destilada homogeneizada e foi determinada a absorbância a $540 \mathrm{~nm}$, contra o branco apropriado.

Para a avaliação da produção de $\beta$-1,3-glucanase foi utilizada a técnica de quantificação colorimétrica de glicose liberada do substrato laminarina, através da dosagem de açúcares redutores. A reação foi realizada com $200 \mu \mathrm{L}$ de tampão Mcllvaine, $\mathrm{pH}$ 6,0; $100 \mu \mathrm{L}$ da amostra de cultivo e $100 \mu \mathrm{L}$ de laminarina $\left(4 \mathrm{mg} \mathrm{mL}^{-1}\right)$. A mistura da reação foi incubada a $50^{\circ} \mathrm{C}$ por 1 hora. Após esse período, a reação foi paralisada com a da adição de $200 \mu \mathrm{L}$ do reagente ADNS à mistura da reação, determinando-se o teor de açúcares redutores liberados. A leitura de absorbância a $540 \mathrm{~nm}$ foi feita contra a mistura de reação contendo tampão em substituição ao meio de cultivo, sendo subtraído de cada amostra o valor do controle negativo que consistiu na mistura da reação na presença de tampão substituindo o substrato. As leituras de absorbâncias foram plotadas em curva padrão para glicose e a atividade enzimática foi expressa em U/L, no qual uma unidade de atividade (U) foi definida como $1 \mathrm{~g}$ de açúcar redutor liberado (glicose) da laminarina nas condições de ensaio.

A avaliação da produção de quitinase foi realizada pela da técnica de $\mathrm{N}$-acetil glucosamina (NAG), a partir do substrato glicol quitina. Para a realização da análise, $100 \mu \mathrm{L}$ da amostra de meio de cultivo da levedura foram misturados com $200 \mu \mathrm{L}$ de tampão Mcllvaine, pH 6,0 e $100 \mu \mathrm{L}$ de glicol quitina $0,01 \%(\mathrm{p} / \mathrm{v})$ neste mesmo tampão. Após incubação por 60 minutos a $50^{\circ} \mathrm{C}$, a reação foi interrompida pela adição de $200 \mu \mathrm{L}$ do reagente ADNS à mistura de reação, determinando-se o teor de açúcares redutores liberados, como citado anteriormente. A cubeta de referência (branco) consistiu na mistura da reação na presença tampão em substituição ao meio de cultivo. $\mathrm{O}$ valor da leitura foi subtraído do obtido pelo controle negativo que apresentou o tampão em substituição ao substrato (glicol quitina). A atividade enzimática foi expressa em U/L, no qual uma unidade de atividade (U) foi definida como $1 \mathrm{~g}$ de açúcar redutor liberado (N-acetilglucosamina) enzimaticamente da glicol quitina, nas condições do ensaio.

\section{Identificação molecular dos isolados de levedura}

Foram identificados oito isolados de levedura (ACBL-78, ACBL-80, ACBL-81, ACBL-82, ACBL-84, ACBL-86, ACBL-87) com base em seu material genético utilizando técnicas de biologia molecular. O DNA das leveduras foi extraído através do kit Wizard Genomic DNA Purification KIT - Promega ${ }^{\circledR}$. A quantidade e a qualidade (pureza) do DNA extraído foram determinadas por densidade óptica usando um espectrofotômetro (NanoDrop 2000c). A amplificação das regiões ITS (Internal Transcribed Spacer) do rDNA, incluindo o gene $5.8 \mathrm{~S}$, foi realizada por PCR utilizando os seguintes primers: forward-ITS1 (TCCGTAGGTGAACCTGCGG) e reverse-ITS4 (TCCTCCGCTTATTGATATGC), de acordo com White et al. (1994). As condições de ciclagem por PCR consistiram num passo de desnaturação inicial a $94{ }^{\circ} \mathrm{C}$ durante $1 \mathrm{~min}$; 30 ciclos de desnaturação a $94^{\circ} \mathrm{C}$ durante 1 min, anelamento a $55^{\circ} \mathrm{C}$ por 2 minutos e extensão a $72{ }^{\circ} \mathrm{C}$ por $2 \mathrm{~min}$; seguido de 1 ciclo final de extensão $72{ }^{\circ} \mathrm{C}$ por 5 minutos. O produto de PCR foi purificado usando o "Kit comercial "Purelink TM Quick Gel Extration and PCR Purification Combo Kit" (Invitrogen ${ }^{\mathrm{TM}}$ ) (Thompson et al., 1994). As sequências foram alinhadas e comparadas com a base de dados NCBI pela Internet usando a Ferramenta de Pesquisa de Alinhamento Local Básico (Altschul et al., 1997).

\section{Análises de estatísticas}

Para todos os ensaios de produção de compostos antifúngicos e para a análise de crescimento micelial do fitopatógeno retirado da zona de antagonismo utilizou-se um delineamento inteiramente casualizado com cinco repetições. Para o teste de competição por nutrientes, utilizou-se um esquema fatorial com oito repetições por tratamento. Os dados foram submetidos à análise de variância (ANOVA) e as médias comparadas pelo teste de Tukey a 5\% de significância. Todos os ensaios foram realizados em duplicata. As análises foram realizadas utilizando o software ASSISTAT.

\section{RESULTADOS}

\section{Produção de compostos antifúngicos pelos isolados de leveduras}

No ensaio realizado para determinação de compostos antifúngicos voláteis, os resultados obtidos mostraram que os isolados de leveduras não foram capazes de produzir metabólitos voláteis que afetassem o tamanho da colônia do patógeno. 
No teste de compostos antifúngicos livres de células, os resultados apresentados na Figura 1 mostraram que somente os isolados ACBL-78 e ACBL- 80 produziram compostos antifúngicos livres de células que reduziram o tamanho da colônia do fitopatógeno.

Com relação ao teste de compostos antifúngicos termoestáveis, os dados obtidos mostraram que os isolados de leveduras ACBL-76, ACBL-81, ACBL-82 e ACBL-84 produziram metabólitos termoestáveis que reduziram, significativamente, o tamanho da colônia do patógeno (Figura 2).

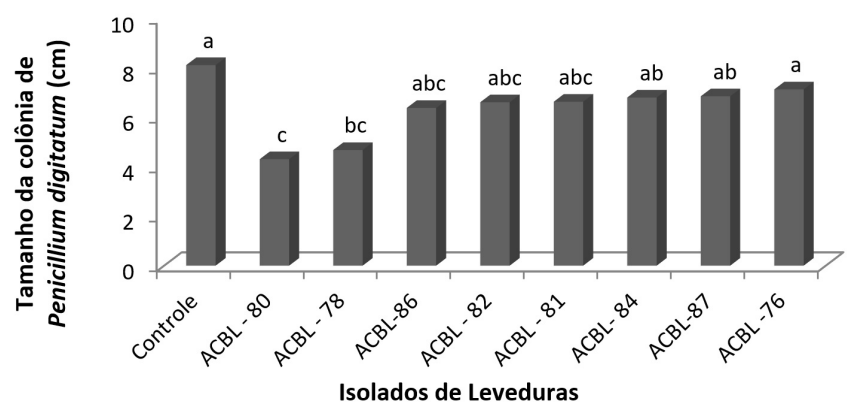

Figura 1. Tamanho da colônia de Penicillium digitatum sob influência de compostos antifúngicos livres de células produzidos pelos diferentes isolados de leveduras. Médias seguidas pela mesma letra não diferem entre si pelo teste de Tukey $(P<0,05)$.

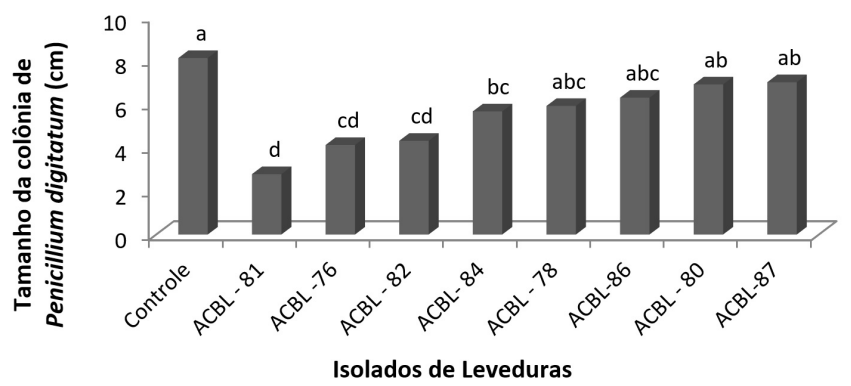

Figura 2. Tamanho da colônia de Penicillium digitatum sob influência de compostos antifúngicos termoestáveis produzidos pelos diferentes isolados de leveduras. Médias seguidas pela mesma letra não diferem entre si pelo teste de Tukey $(P<0,05)$.

\section{Detecção da atividade killer}

No ensaio utilizado para se determinar a atividade killer pelas leveduras testadas, observou-se que todos os isolados apresentaram resultados positivos quanto à atividade killer. Como observado na Tabela 1, isolados apresentaram linha ou zona azul (morte celular) ou zona clara (inibição, porém sem morte celular) ao redor da colônia, indicando a ação killer sobre a levedura sensível (Figura 3).

\section{Competição por nutrientes}

No ensaio realizado para determinar se as leveduras testadas competem com o fitopatógeno pelos nutrientes, os resultados mostraram que a levedura não compete pela fonte de carbono, evidenciando, inclusive, que o açúcar favoreceu o fitopatógeno, com uma dimuição na porcentagem de conídios não germinados em função do aumento da fonte de glicose. No entanto, pode-se dizer que todos os isolados de leveduras inibiram a germinação dos conídios de $P$. digitatum (Figura 4), independente da fonte de carbono. Os isolados ACBL-84, ACBL-78 e ACBL-76 foram os que proporcionaram maiores valores de inibições da germinação de conídios do patógeno, proporcionando $96,63 \%, 94,81 \%$ e $94,26 \%$ de inibição, respectivamente. A inibição de conídios foi diminuindo conforme foi aumentando a concentração de glicose (Figura 5).

Tabela 1. Atividade killer dos isolados de leveduras em relação à levedura sensível S. cerevisiae NCYC $1006 \mathrm{em}$ meio YEPD-azul de metileno, a $28^{\circ} \mathrm{C}$, $\mathrm{pH} 4,5$

\begin{tabular}{cc}
\hline Isolados de leveduras & Atividade Killer \\
\hline ACBL-76 & Zona Clara \\
ACBL-78 & Zona Azul \\
ACBL-80 & Zona Clara \\
ACBL-81 & Zona Clara; Zona Azul, Halo \\
ACBL-82 & Zona Clara \\
ACBL-84 & Linha Azul \\
ACBL-86 & Zona Azul \\
ACBL-87 & Zona Clara; Linha Azul \\
\hline
\end{tabular}




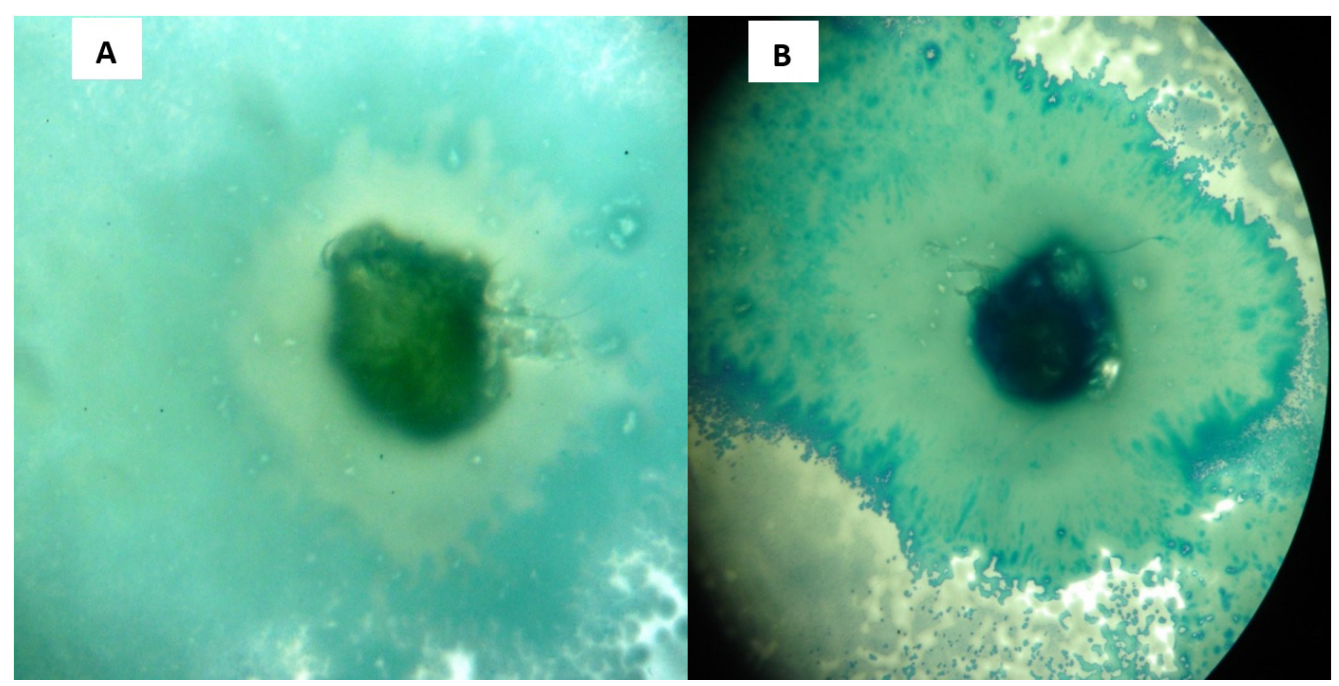

Figura 3. Atividade killer do ACBL-80 mostrando a zona clara (inibição da levedura sensível S. cerevisiae NCYC 1006) em YEPD-azul de metileno, a $28^{\circ} \mathrm{C}$, pH 4,5 (A). Atividade Killer do ACBL- 81 mostrando o halo azul (morte celular da levedura sensível S. cerevisiae NCYC 1006) em YEPD-azul de metileno, a $28{ }^{\circ} \mathrm{C}, \mathrm{pH} 4,5$ (B).

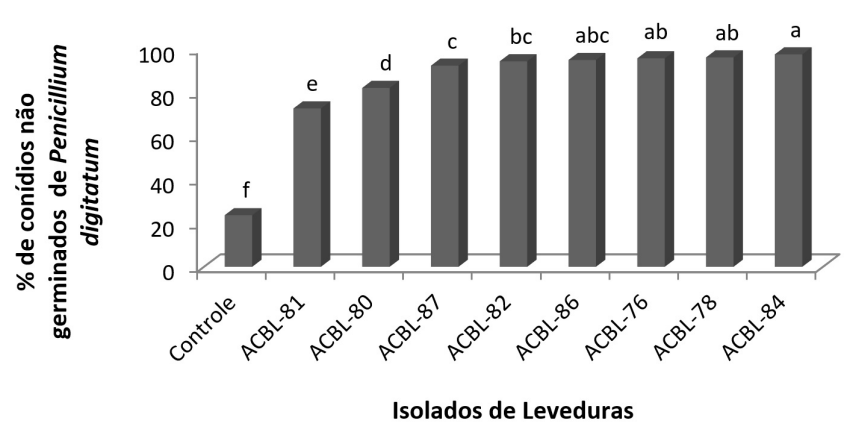

Figura 4. Porcentagem de conídios não germinados do fungo Peniciliium digitatum sob ação das leveduras em meio ágar-água com diferentes concentrações de glicose, a $26^{\circ} \mathrm{C}$. Médias seguidas pela mesma letra não diferem entre si pelo teste de Tukey $(P<0,05)$.

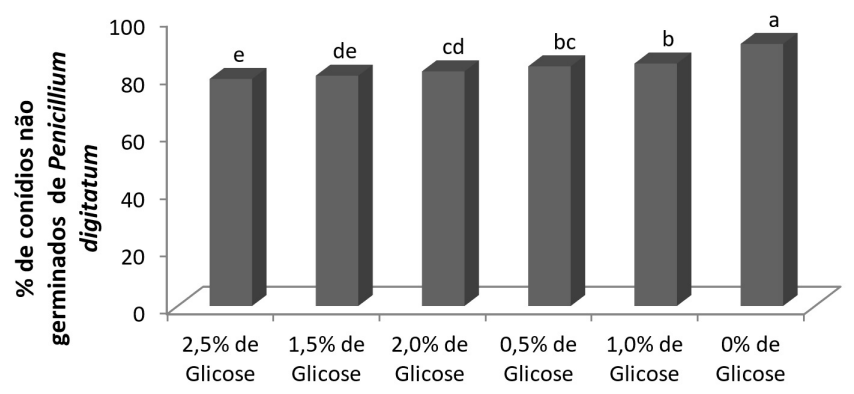

Figura 5. Porcentagem de conídios não germinados do fungo Penicillium digitatum sob ação das leveduras em meio ágar-água com diferentes concentrações de glicose, a $26^{\circ} \mathrm{C}$. Médias seguidas pela mesma letra não diferem entre si pelo teste de Tukey $(P<0,05)$.

\section{Avaliação do crescimento micelial do fitopatógeno retirado da zona de antagonismo}

A avaliação do crescimento micelial do $P$. digitatum, após a sua hifa ser retirada da zona de antagonismo, com os diferentes isolados de leveduras, mostrou que os isolados de leveduras não afetaram a viabilidade das hifas do fitopatógeno. Quando o fungo foi retirado da região mediana (próxima ao halo de inibição) ou, longe da levedura, o crescimento do patógeno não foi afetado, apresentando crescimento normal.

\section{Produção de enzimas hidrolíticas}

Para o ensaio onde se determinou a capacidade dos isolados de levedura produzir enzimas hidrolíticas, verificou-se que todos produziram atividade enzimática para quitinase, não apresentando atividade enzimática para $\beta$-1,3-glucanase (Tabela 2).

\section{Identificação molecular dos isolados de levedura}

Os isolados de levedura utilizados neste estudo foram identificados como: Saccharomyces cerevisiae (ACBL-76, ACBL-78, ACBL-80, ACBL-81 e ACBL-82), Candida stellimalicola (ACBL-84) e Meyerozyma caribbica (ACBL-86). 
Tabela 2. Produção de quitinase e $\beta$-1,3-glucanase por isolados de leveduras, avaliada através da produção de açúcar redutor

\begin{tabular}{ccc}
\hline Isolados & Quitinase AR $(\mathrm{g} / \mathrm{L})^{(1)}$ & $\beta$-1,3-glucanase AR $(\mathrm{g} / \mathrm{L})^{(1)}$ \\
\hline ACBL-76 & 0,074 & 0 \\
ACBL-78 & 0,059 & 0 \\
ACBL-80 & 0,06 & 0 \\
ACBL-81 & 0,064 & 0 \\
ACBL-82 & 0,073 & 0 \\
ACBL-84 & 0,079 & 0 \\
ACBL-86 & 0,055 & 0 \\
ACBL-87 & 0,063 & 0 \\
\hline
\end{tabular}

${ }^{(1)} \mathrm{AR}-$ Açúcar redutor.

\section{DISCUSSÃO}

O respectivo estudo teve como objetivo avaliar os mecanismos de ação de oito isolados de leveduras que apresentam potencial para o biocontrole do bolor verde em frutos cítricos. Compreender o mecanismo de ação de agentes de biocontrole é importante, principalmente, quando se pretendem obter métodos de produção e formulações de bioprodutos mais consistentes.

Os resultados apresentados neste trabalho mostraram que, com exceção do ACBL-86 e ACBL-87, os demais isolados de leveduras produziram substâncias antifúngicas em quantidades suficientes para inibirem o desenvolvimento micelial de $P$. digitatum. ACBL-76, ACBL-81, ACBL-82 e ACBL-84 produziram substâncias que apresentaram atividade antimicrobiana somente quando as mesmas foram submetidas à alta temperatura (Figura 2). Possivelmente, componentes presentes nas células dessas leveduras foram responsáveis pelo antagonismo, necessitando, porém, da autoclavagem para serem liberados ao meio de cultura. Por outro lado, embora os isolados ACBL-78 e ACBL-80 tenham produzidos metabólitos livres de células do antagônico que afetaram o desenvolvimento do patógeno, essas substâncias não suportaram a alta temperatura (Figura 1). Lima et al. (2013) ao estudarem a produção de compostos antifúngicos por leveduras, verificaram que suspensões livres de células e de metabólitos termoestáveis não tiveram nenhum efeito no desenvolvimento de Colletotrichum gloeosporioides, não corroborando com os resultados encontrados neste estudo.

Verificou-se que, todas as leveduras testadas mostraram resultados positivos referente ao fator killer mostrando ser esse o possível mecanismo de ação adotado no biocontrole de P. digitatum (Tabela 1). Esses resultados estão de acordo com os obtidos por outros autores. Segundo Platania et al. (2012),
Wickerhamomyces anomalus, quando cultivado sobre meio acidificado, demonstrou atividade micocinogênica contra P. digitatum, como indicado pelo grande halo de inibição e danos sobre as hifas do fitopatógeno em decorrência da atividade de $\beta$-glucanase. Portes et al. (2013) também avaliaram o antagonismo das leveduras Candida globrata, C. albidans, S. cerevisiae e Pichia kluyveri, produtoras de toxina killer contra P. expansum e Aspergillus ochraceus, observando que tal produção foi eficiente no controle dos dois fitopatógenos.

A competição por nutrientes não foi um dos mecanismos de ação adotado pelas leveduras testadas neste estudo, uma vez que, o aumento da concentração de glicose não favoreceu o antagonismo (Figura 4 e 5). Dados similares foram obtidos por Lutz et al. (2013), onde relataram que a capacidade de biocontrole de várias leveduras à $P$. expansum foi significativamente afetada, de forma negativa, na presença de uma fonte de açúcar. Porém, outros autores não corroboram com esses resultados. Castoria et al. (2001), por exemplo, relataram ser a competição por nutrientes um dos mecanismos de ação da levedura Aureobasidium pullulans (LS-30), um antagonista importante de vários patógenos que ocorrem na pós-colheita, como Botrytis cinerea, P. expansum, Rhizopus stolonifer e Aspergillus niger. Mekbib et al. (2011) ao estudarem o modo de ação das leveduras Cryptococcus laurentii e $C$. sake para controle de $P$. digitatum, notaram que a competição por nutrientes (extrato de casca de laranja e extrato de malte) é provavelmente o principal modo de ação desses microrganismos, pois favoreceram a ação antagônica das leveduras na inibição da germinação do patógeno. Resultados semelhantes, também, foram relatados por Bautista-Rosales et al. (2013) ao estudarem o mecanismo de ação de Meyerozyma caribbica no controle de C. gloeosporioides, onde a competição por nutrientes, 
principalmente quando a sacarose foi usada como fonte de carbono, foi apontada como um dos principais modo de ação da levedura.

A maioria dos isolados de leveduras testada apresentou múltiplos mecanismos de ação que possam estar envolvidos na eficiência de biocontrole de $P$. digitatum. Resultados indicaram que os mecanismos de ação, tais como, a produção de substâncias antifúngicas, atividade killer, atividade enzimática (produção de quitinase) e a inibição da germinação de conídios do patógeno foram as atividades antagônicas mais importantes apresentadas pelas leveduras, o que poderia explicar as porcentagens de inibições (acima de 80\%) das colônias de Penicillium promovidas pelos isolados ACBL-82, ACBL-84 e ACBL-76. Dados semelhantes foram encontrados por Lutz et al. (2013) ao estudarem os possíveis mecanismos de ação associados ao biocontrole das leveduras Cryptoccocus albidus, Pichia membranifaciens e Cryptoccocus victoriae contra $P$. expansum e $B$. cinerea. Segundo os autores, os isolados de leveduras exibiram diferentes mecanismos, tais como, a colonização de ferimentos, inibição da germinação, secreção de toxinas killer e, principalmente, a produção de enzimas hidrolíticas, como protease, quitinase e glucanase. A produção de quitinase por leveduras (Metschnikowia pulcherrima e Rhodotorula sp.) também foi constatado por Saravanakumar et al. (2009) contra $B$. cinerea em maçãs. Os autores notaram que M. pulcherrima apresentou maior produção da enzima em relação a Rhodotorula sp., quando na presença da parede celular do fitopatógeno, como observado no presente estudo, onde todos os isolados de leveduras testados apresentaram produção de quitinase na presença da parede de Penicillium (Tabela 2).

Nosso estudo sugere que os isolados ACBL-80, ACBL-82 e ACBL-86 apresentaram múltiplos mecanismos de ação, tais como, produção de toxina killer, atividade enzimática (produção de quitinase) e inibição da germinação de conídios do patógeno; além da produção de substâncias antifúngicas pelos isolados ACBL-80 e ACBL-82. Mecanismos esses, que, podem estar relacionados com a eficiência do controle in vivo do bolor verde previamente relatado no trabalho de Cunha, 2013.

\section{AGRADECIMENTOS}

À Fapesp (Fundação de Amparo à Pesquisa do Estado de São Paulo) pelo suporte financeiro (Proc. n. 2011/13006-1).

\section{REFERÊNCIAS}

Altschul, S. F., Madden, T. L., Schaffer, A. A., Zhang, J., Zhang, Z., Miller, W., \& Lipman, D. J. (1997). Gapped BLAST and PSI-BLAST: a new generation of protein database search programs. Nucleic Acids Research, 25(17), 3389-3402. http://dx.doi.org/10.1093/nar/25.17.3389. PMid:9254694.

Bar-Shimon, M., Yehuda, H., Cohen, L., Weiss, B., Kobeshnikov, A., Daus, A., Goldway, M., Wisniewski, M., \& Droby, S. (2004). Characterization of extracellular lytic enzymes produced by the yeast biocontrol agent Candida oleophila. Current Genetics, 45(3), 140-148. http://dx.doi. org/10.1007/s00294-003-0471-7. PMid:14716497.

Bautista-Rosales, P. U., Calderon-Santoyo, M., ServínVillegas, R., Ochoa-Álvarez, N. A., \& Ragazzo-Sánchez, J. A. (2013). Action mechanisms of the yeast Meyerozyma caribbica for the control of the phytopathogen Colletotrichum gloeosporioides in mangoes. Biological Control, 65(3), 293-301. http://dx.doi.org/10.1016/j.biocontrol.2013.03.010.

Boubaker, H., Saadi, B., Boudyach, E. H., \& Benaoumar, A. A. (2009). Sensitivity of Penicillium digitatum and P. italicum to imazalil and thiabendazole in Morocco. Plant Pathology Journal, 8(4), 152-158. http://dx.doi. org/10.3923/ppj.2009.152.158.

Bus, V. G., Bongers, A. J., \& Risse, L. A. (1991). Occurrence of Penicillium digitatum and Penicillium italicum resistent to benomyl, thiabendazlole, and imazalil on citrus fruit from different geographic origens. Plant Disease, 75(11), 1098-1100. http://dx.doi.org/10.1094/PD-75-1098.

Castoria, R., De Curtis, F., Lima, G., Caputo, L., Pacifico, S., \& De Cicco, V. (2001). Aureobasidium pullulans (LS-30) an antagonistic of postharvest pathogens of fruits: study on its mode of action. Postharvest Biology and Technology, 22(1), 7-17. http://dx.doi.org/10.1016/ S0925-5214(00)00186-1.

Ceccato-Antonini, S. R., Tosta, C. D., \& Silva, A. C. (2004). Determination of yeast Killer activity in fermentation sugarcane juice using selected ethanol-making strains. Brazilian Archives of Biology and Technology, 47(1), 13-23. http://dx.doi.org/10.1590/S1516-89132004000100003.

Cunha, T. (2013). Potencial de leveduras isoladas do solo e do filoplano de plantas citricas no biocontrole de doenças de pós-colheita de citros (Dissertação de mestrado). Faculdade de Ciências Agrárias e Veterinárias, 
Universidade Estadual Paulista "Julio de Mesquita Filho", Jaboticabal.

Dennis, C., \& Webster, J. (1971). Antagonistic properties of species groups of Trichoderma. III. Hyphal interaction. Transactions of the British Mycological Society, 57(3), 363-369. http://dx.doi.org/10.1016/S0007-1536(71)80050-5.

Droby, S., Vinokur, V., Weiss, B., Cohen, L., Daus, A., Goldschmidt, E. E., \& Porat, R. (2002). Induction of resistance to Penicillium digitatum in grapefruit by the yeast biocontrol agent Candida oleophila. Phytopathology, 92(4), 393-399. http://dx.doi.org/10.1094/PHYTO.2002.92.4.393. PMid:18942952.

Duffy, B., Schouten, A., \& Raaijmakers, J. M. (2003). Pathogen self-defense: mechanisms to counteract microbial antagonism. Annual Review of Phytopathology, 41(1), 501-538. http://dx.doi.org/10.1146/annurev. phyto.41.052002.095606. PMid:12730392.

Eckert, J. W., \& Eaks, I. L. (1989). Postharvest disorders and diseases of citrus fruits. In W. Reuter, E. C. Calavan, \& G. E. Carman (Eds.), The citrus industry (Vol. 5). Berkeley: University of California Press.

Fialho, M. B. (2005). Efeito in vitro de Saccharomyces cerevisiae sobre Guignardia citricatrpa, agente causal da pinta preta dos citros (Dissertação de mestrado). Escola Superior de Agricultura “Luiz de Queiroz", Universidade de São Paulo, Piracicaba.

Filonow, A. B. (1998). Role of competition for sugars by yeast in the biocontrol of gray mold of apple. Biocontrol Science and Technology, 8(2), 243-256. http://dx.doi. org/10.1080/09583159830315.

Franco, D. A. S., \& Bettiol, W. (2000). Controle de bolor verde em pós-colheita de citros com produtos alternativos (pp. 1-4, Pesquisa em Andamento, Vol. 10). Jaguariúna: Embrapa Meio Ambiente. Recuperado em 19 de março de 2014, de http:/www.infoteca.cnptia.embrapa.br/ bitstream/doc/14565/1/controledebolor.pdf

Frigheto, R. T. S., \& Melo, I. S. (1995). Produção de antibióticos por microrganismos. In I. S. Melo, \& R. M. V. Sanhuez (Eds.), Métodos de seleção de microrganismos antagônicos a fitopatógenos (pp. 40-46). Jaguariúna: Embrapa Meio Ambiente.

Fundo de Defesa da Citricultura - FUNDECITRUS. (2017). Estimativa da safra de laranja Parque Citrícola de São Paulo e Triângulo/Sudoeste Mineiro. Araraquara.
Recuperado em 25 de fevereiro de 2017, de http://www. fundecitrus.com.br/pes/estimativa

Ismail, M., \& Zhang, J. (2004). Postharvest citrus diseases and their control. Outlooks on Pest Management, 15(1), 29-35. http://dx.doi.org/10.1564/15feb12.

Jijakli, M. H., \& Lepoivre, P. (1998). Characterization of na exo- $\beta$-1,3-glucanase produced by Pichia anomala strain K, antagonist of Botrytis cinerea on apples. Phytopathology, 88(4), 335-343. http://dx.doi.org/10.1094/ PHYTO.1998.88.4.335. PMid:18944957.

Kinay, P., Mansour, M. F., Mlikota Gabler, F., Margosan, D. A., \& Smilanick, J. L. (2007). Characterization of fungicide-resistant isolates of Penicillium digitatum collected in California. Crop Protection, 26(4), 647-656. http://dx.doi.org/10.1016/j.cropro.2006.06.002.

Kupper, K. C., Cervantes, A. L. L., Klein, M. N., \& Silva, A. C. (2013). Avaliação de micro-organismos antagônicos, Saccharomyces cerevisiae e Bacillus subtilis para o controle de Penicillium digitatum. Revista Brasileira de Fruticultura, 35(2), 425-436. http://dx.doi.org/10.1590/ S0100-29452013000200011.

Lima, J. R., Gonçalves, L. R. B., Brandão, L. R., Rosa, C. A., \& Viana, F. M. P. (2013). Isolation, identification, and activity in vitro of killer yeasts against Colletotrichum gloeosporioides isolated from tropical fruits. Journal of Basic Microbiology, 53(7), 590-599. http://dx.doi. org/10.1002/jobm.201200049. PMid:22915228.

Lopes, M. R., Klein, M. N., Ferraz, L. P., Silva, A. C., \& Kupper, K. C. (2015). Saccharomyces cerevisiae: a novel and efficient biological control agent for Colletotrichum acutatum during pre-harvest. Microbiological Research, 175, 93-99. http://dx.doi.org/10.1016/j.micres.2015.04.003. PMid:25960430.

Lutz, M. C., Lopes, C. A., Rodriguez, M. E., Sosa, M. C., \& Sangorrín, M. P. (2013). Efficacy and putative mode of action of native and commercial antagonistic yeasts against postharvest pathogens of pear. International Journal of Food Microbiology, 164(2-3), 166-172. http://dx.doi. org/10.1016/j.ijfoodmicro.2013.04.005. PMid:23680800.

Masih, E. I., Slezack-Deschaumes, S., Marmaras, I., Barka, E. A., Vernet, G., Charpentier, C., Adholeya, A., $\&$ Paul, B. (2001). Characterisation of the yeast Pichia membranifaciens and its possible use in the biological control of Botrytis cinerea. FEMS Microbiology Letters, 202(2), 227-232. http://dx.doi.org/10.1111/j.1574-6968.2001. tb10808.x. PMid:11520619. 
Mekbib, S. B., Regnier, T. J. C., \& Korsten, L. (2011). Efficacy and mode of action of yeasts antagonistics for control of Penicillium digitatum in oranges. Tropical Plant Pathology, 36, 233-240.

Miller, G. H. (1959). Use of dinitrosalicylic acid reagent for determination of reducing sugar. Analytical Chemistry, 31(3), 426-428. http://dx.doi.org/10.1021/ac60147a030.

Palou, L., Usall, J., Munoz, A., Smilanick, J. L., \& Vinas, I. (2002). Hot water, sodium carbonate, and sodium bicarbonate for the control of postharvest green and blue molds of clementine mandarins. Postharvest Biology and Technology, 24(1), 93-96. http://dx.doi.org/10.1016/ S0925-5214(01)00178-8.

Platania, C., Restuccia, C., Muccilli, S., \& Cirvilleri, G. (2012). Efficacy of killer yeasts in the biological control of Penicillium digitatum on Tarocco Orange frutis (Citrus sinensis). Food Microbiology, 30(1), 219-225. http:// dx.doi.org/10.1016/j.fm.2011.12.010. PMid:22265304.

Portes, C. S., Oliveira, A. V., Simer, P., Lunkes, A. M., \& Coelho, A. R. (2013). Role of killer factors in the inhibitory activity of bio-control yeasts against Penicillium expansum and Aspergillus ochraceus. Brazilian Archives of Biology and Technology, 56(4), 619-627. http://dx.doi. org/10.1590/S1516-89132013000400012.

Rosa-Magri, M. M., Tauk-Tornisielo, S. M., \& CeccatoAntonini, S. R. (2011). Bioprospection of yeasts as biocontrol agents against phytopathogenic molds. Brazilian Archives of Biology and Technology, 54(1), 1-5. http:// dx.doi.org/10.1590/S1516-89132011000100001.

Saligkarias, I. D., Gravanis, F. T., \& Eptona, H. A. S. (2002). Biological control of Botrytis cinerea on tomato plants by the use of epiphytic yeasts Candida guilliermondii strains 101 and US 7 and Candida oleophila strain I-182: II. a study on mode of action. Biological Control, 25, 151-161.

Santos, A., Sanchez, A., \& Marquina, D. (2004). Yeasts as biological agents to control Botrytis cinerea. Microbiological
Research, 159(4), 331-338. http://dx.doi.org/10.1016/j. micres.2004.07.001. PMid:15646379.

Saravanakumar, D., Spadaro, D., Garibaldi, A., \& Gullino, M. L. (2009). Detection of enzymatic activity and partial sequence of a chitinase gene in Metschnikowia pulcherrima strain MACH1 used as post-harvest biocontrol agent. European Journal of Plant Pathology, 123(2), 183-193. http://dx.doi.org/10.1007/s10658-008-9355-5.

Schmidt, L. S., Ghosoph, J. M., Margosan, D. A., \& Smilanick, J. L. (2006). Mutation at $\beta$-Tubulin Codon 200 Indicated Thiabendazole Resistance in Penicillium digitatum Collected from California Citrus Packinghouses. Plant Disease, 90, 765-777. http://dx.doi.org/10.1094/ PD-90-0765.

Thompson, J. D., Higgins, D. G., \& Gibson, T. J. (1994). Improving the sensitivity of progressive multiple sequence alignment through sequence weighting, position-specific gap penalties and weight matrix choice. Nucleic Acids Research, 22(22), 4673-4680.

White, T. J., Bruns, T., Lee, S., \& Taylor, J. (1994). Amplification and direct sequencing of fungal ribosomal RNA genes for phylogenetics. In M. Innis, D. H. Gelfand, J. J. Sninsky, \& T. J. White (Eds.), PCR protocols: a guide to methods and applications (pp. 315-321). New York: Academic Press.

Zhu, J. W., Xie, Q. Y., \& Li, H. Y. (2006). Occorrence of imazalil-resistance biotype of Penicillium digitatum in China and the resistance molecular mechanism. Journal of Zhejiang University. Science, 7(S2), 362-365. http:// dx.doi.org/10.1631/jzus.2006.AS0362.

Recebido: Abril 04, 2017 Aceito: Janeiro 15, 2018

Como citar: Ferraz, L. P., Cunha, T., \& Kupper, K. C. (2018). Mecanismos de ação de isolados de leveduras envolvidos no biocontrole de Penicillium digitatum, agente causal do bolor verde em frutos cítricos. Citrus Research and Technology, 39, e-1033. http://dx.doi.org/10.4322/crt.17101 